\title{
Pillar[5]arene-Based Molecular Recognition Induced Crystal-to-Crystal Transformation and Its Application in Adsorption of Adiponitrile in Water
}

Bingbing Shi,${ }^{\dagger}$ Liqing Shangguan, ${ }^{\dagger}$ Huanhuan Wang, ${ }^{\dagger}$ Huangtianzhi Zhu, ${ }^{\dagger}$ Hao Xing, ${ }^{\dagger}$ Peiren Liu,,${ }^{\dagger}$ Yuezhou Liu, ${ }^{\dagger}$ Jiyong Liu, ${ }^{\dagger}$ and Feihe Huang ${ }^{\dagger, *}$

'State Key Laboratory of Chemical Engineering, Center for Chemistry of High-Performance \& Novel Materials, Department of Chemistry, Zhejiang University, Hangzhou, Zhejiang 310027 (China) Fax: (+86) 571-87953189; E-mail: fhuang@zju.edu.cn

${ }^{*}$ MOE Key Laboratory of Macromolecular Synthesis and Functionalization, Department of Polymer Science and Engineering, Zhejiang University, Hangzhou, Zhejiang 310027 (China)

\section{Supporting Information (13 pages)}

1. Materials and methods S2

2. Synthesis of compound NP5 S4

3. Single-crystal structure of NP5 S8

4. Host-guest studies between NP5 and adiponitrile S8

5. Single-crystal structure of NP5/adiponitrile complex S9

6. Powder X-ray diffraction studies S10

7. Thermogravimetric analysis S10

8. Amorphous solid of NP5 adsorption studies S11

9. NP5 regeneration studies

10. References S12

11. Crystallography Report 


\section{Materials and methods}

All reagents were commercially available and used as supplied without further purification. Solvents were either employed as purchased or dried according to procedures described in the literature.

${ }^{1} \mathrm{H}$ NMR and ${ }^{13} \mathrm{C}$ HMR spectra were recorded with a Bruker Avance DMX 600 or a Bruker Avance DMX 500 spectrophotometer using the deuterated solvent as the lock and the residual solvent or TMS as the internal reference.

The single crystals data were collected on an Oxford Diffraction Xcalibur Atlas Gemini captra. High-resolution mass spectrometric experiments were performed with a Bruker 7-Tesla FT-ICR mass spectrometer equipped with an electrospray source (Billerica, MA, USA).

Thermogravimetric analysis (TGA) was carried out using a Q5000IR analyzer (TA instruments) with an automated vertical overhead thermobalance. The samples were heated at the rate of $10{ }^{\circ} \mathrm{C} / \mathrm{min}$ using $\mathrm{N}_{2}$ as the protective gas.

Laboratory powder X-ray diffraction (PXRD) data were collected in transmission mode on samples held on thin Mylar film in aluminum well plates on a Panalytical X'Pert PRO MPD equipped with a high throughput screening (HTS) XYZ stage, X-ray focusing mirror, and PIXcel detector, using Ni-filtered $\mathrm{Cu}$ $\mathrm{K} \alpha$ radiation. Data were measured over the range of $5-50^{\circ}$ in $\sim 0.013^{\circ}$ steps over $60 \mathrm{~min}$. PXRD data before and after adsorption were collected on a Rigaku Ultimate-IV X-ray diffractometer operating at 40 $\mathrm{kV} / 30 \mathrm{~mA}$ using the $\mathrm{Cu} \mathrm{K \alpha}$ line $\left(\lambda=1.5418 \AA\right.$ ). Data were measured over the range of $5-40^{\circ}$ in $5^{\circ} / \mathrm{min}$ steps over 7 min. Indexing and Le Bail refinements were performed using TOPAS-Academic version.

Single-crystal growth was performed via the following method: $0.25 \mathrm{~g}$ of dry NP5 powder was put in a small vial where $5 \mathrm{~mL}$ of acetonitrile was added. The resultant solution was allowed to evaporate slowly to give light yellow NP5 crystals in 2 to 3 days.

Single-crystal-to-single-crystal transformation experiments were performed as follow: $5 \mathrm{mg}$ of NP5 single crystals were put in a small vial where $15 \mathrm{~mL}$ of an adiponitrile water solution $(0.8 \mathrm{~mol} / \mathrm{L})$ were added. The resultant solutions were allowed to stand at room temperature for 5 days to get the NP5/adiponitrile single crystals. 
Adiponitrile adsorption and removal experiments were performed at room temperature $\left(25.0^{\circ} \mathrm{C}\right)$ in water. The NP5 single crystals or amorphous solid of NP5 (100 mg) were washed with $\mathrm{H}_{2} \mathrm{O}$ for 5 min and then filtered on Whatman filter paper. Then, the NP5 single crystals or amorphous solid of NP5 were transferred to a $25.0 \mathrm{~mL}$ round bottomed flask. An adiponitrile stock $\mathrm{H}_{2} \mathrm{O}$ solution $(1.00 \mathrm{mmol} / \mathrm{L}, 10.0$ $\mathrm{mL}$ ) was added to the round bottomed flask. The mixtures were allowed to stand at room temperature for 5 days and the suspension in the flask $(1.00 \mathrm{~mL})$ was taken by a syringe at certain intervals and then filtered immediately using a LABMAX $0.2 \mu \mathrm{m}$ inorganic membrane filter. The filtrate was concentrated at $120{ }^{\circ} \mathrm{C}$ and then $1.00 \mathrm{~mL}$ of acetic acid $\mathrm{D}_{2} \mathrm{O}$ solution $(c=1.00 \mathrm{mmol} / \mathrm{L})$ was added. ${ }^{1} \mathrm{H}$ NMR experiment was performed to determine the residual concentration of adiponitrile using acetic acid as the internal standard $(c=1.00 \mathrm{mmol} / \mathrm{L})$ in each sample.

The efficiency of adiponitrile removal by the NP5 single crystal or amorphous solid of NP5 was determined by the following equation: ${ }^{\mathrm{S} 1}$

$$
\% \text { Adiponitrile removal efficiency }=\frac{\left(C_{0}-C_{\mathrm{t}}\right)}{C_{0}} \times 100 \%
$$

where $C_{0}(\mathrm{mM})$ and $C_{\mathrm{t}}(\mathrm{mM})$ are the initial and residual concentrations of the adiponitrile in the stock solution and filtrate, respectively.

NP5 regeneration experiments were performed via the following method: adiponitrile-adsorbed crystals were dissolved in methylene chloride. Then, methanol was added to the solution of NP5 and adiponitrile. The precipitate of NP5 was collected by filtration. Then, NP5 single crystals were regained by crystallization of the NP5 powder in acetonitrile. 
Scheme S1. Synthetic route to naphthalene derivatived pillar[5]arene NP5.

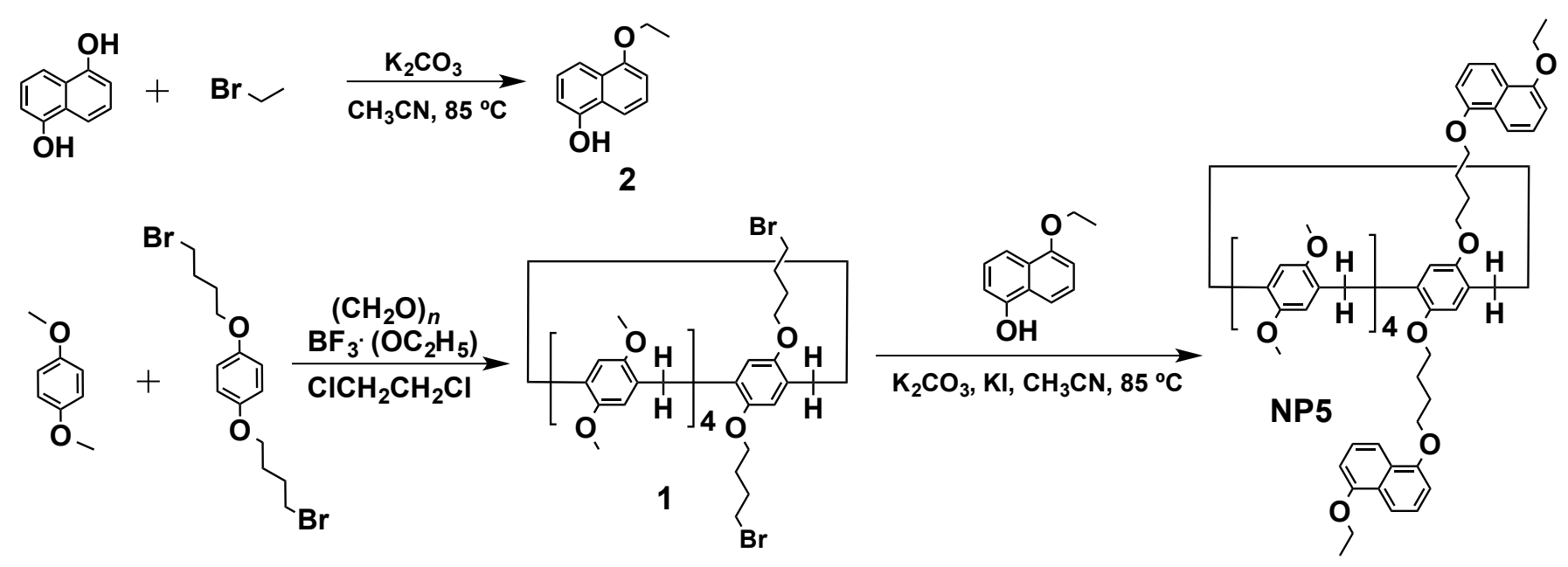

5-ethoxynaphthalen-1-ol (2). In a $250 \mathrm{~mL}$ round bottom flask, 1,5-dihydroxy naphthalene (3.2 g, 20 mmol), $\mathrm{K}_{2} \mathrm{CO}_{3}(11.0 \mathrm{~g}, 80 \mathrm{mmol})$, bromoethane $(2.2 \mathrm{~g}, 20 \mathrm{mmol})$ and $\mathrm{CH}_{3} \mathrm{CN}(150 \mathrm{~mL})$ were added. The reaction mixture was stirred at reflux for 24 hours. After the solid was filtered off, the solvent was removed. The residue was dissolved in $\mathrm{CHCl}_{3}(150 \mathrm{~mL})$ and washed twice with $\mathrm{H}_{2} \mathrm{O}(200 \mathrm{~mL})$. The organic layer was dried over anhydrous $\mathrm{Na}_{2} \mathrm{SO}_{4}$ and evaporated to afford the crude product, which was isolated by flash column chromatography using petroleum ether/ethyl acetate $(v: v=5: 1)$. The fractions containing the product were combined and concentrated to give compound $2(0.80 \mathrm{~g}, 20 \%)$ as an orange solid. The ${ }^{1} \mathrm{H}$ NMR spectrum of compound 2 is shown in Figure S1. ${ }^{1} \mathrm{H}$ NMR $\left(600 \mathrm{MHz}, \mathrm{CDCl}_{3}, 298 \mathrm{~K}\right)$ $\delta$ (ppm): 7.87-7.89 (d, $J=12,1 \mathrm{H}), 7.00-7.11(\mathrm{~d}, J=6,1 \mathrm{H}), 7.36-7.38(\mathrm{t}, J=12,1 \mathrm{H}), 7.27-7.30(\mathrm{t}, J=$ $18,1 \mathrm{H}), 6.82-6.85(\mathrm{t}, J=18,2 \mathrm{H}), 5.16(\mathrm{~s}, 1 \mathrm{H}), 4.18-4.21(\mathrm{~m}, 2 \mathrm{H}), 1.53-1.55(\mathrm{t}, J=12,3 \mathrm{H})$.

Pillar[5] arene derivative $1 .{ }^{\mathrm{S} 2}$ To a solution of 1,4-bis(4-bromobutoxy)benzene (1.9 g, $\left.5 \mathrm{mmol}\right)$ and 1,4dimethoxybenzene $(5.5 \mathrm{~g}, 40 \mathrm{mmol})$ in 1,2-dichloroethane $(80 \mathrm{~mL})$, paraformaldehyde $(1.5 \mathrm{~g}, 50 \mathrm{mmol})$ was added. Then, boron trifluoride diethyl etherate $(6.4 \mathrm{~mL}, 50 \mathrm{mmol})$ was added to the solution and the mixture was stirred at room temperature for 30 minutes. The solution was poured into methanol and the resulting precipitate was collected by filtration. The solid was treated with $\mathrm{CHCl}_{3}(150 \mathrm{~mL})$ and the insoluble part was filtered off. The organic layer was washed twice with $\mathrm{H}_{2} \mathrm{O}(100 \mathrm{~mL})$, dried over anhydrous $\mathrm{Na}_{2} \mathrm{SO}_{4}$ and evaporated to afford the crude product. The crude product was purified by column chromatography on silica gel using the mixture of petroleum ether/ethyl acetate $(v: v=10: 1)$ as an eluent to give $0.70 \mathrm{~g}$ ( $15 \%$ yield) of $\mathbf{1}$ as a white solid. The ${ }^{1} \mathrm{H}$ NMR spectrum of compound $\mathbf{1}$ is shown in Figure S2. ${ }^{1} \mathrm{H}$ NMR (600 MHz, $\left.\mathrm{CDCl}_{3}, 298 \mathrm{~K}\right) \delta(\mathrm{ppm}): 6.72-6.80(\mathrm{~m}, 10 \mathrm{H}), 3.81-3.84(\mathrm{t}, J=18,4 \mathrm{H})$, 3.77-3.78 (m, 10H), 3.65-3.72 (m, 24H), 3.25-3.29 (m, 4H), 1.86-1.88 (m, 4H), 1.78-1.80 (m, 4H); The 
${ }^{13} \mathrm{C}$ NMR spectrum of compound 1 is shown in Figure $\mathrm{S} 3 .{ }^{13} \mathrm{C} \mathrm{NMR}\left(150 \mathrm{MHz}, \mathrm{CDCl}_{3}, 298 \mathrm{~K}\right) \delta(\mathrm{ppm})$ : $150.78,150.73,150.68,150.56,149.81,128.42$, 128.28, 128.25, 128.18, 128.07, 114.85, 114.14, 114.09, $113.90,113.69,67.31,55.97,55.78,55.71,53.16,33.43,29.74,29.45,29.24,28.34$.

Pillar[5] arene derivative NP5. In a $100 \mathrm{~mL}$ round bottom flask, compound 1 (1.9 g, 2 mmol), $\mathrm{K}_{2} \mathrm{CO}_{3}$ (5.5 g, $40 \mathrm{mmol})$, KI (0.08 g, $0.5 \mathrm{mmol})$, compound $2(0.9 \mathrm{~g}, 5 \mathrm{mmol})$ and $\mathrm{CH}_{3} \mathrm{CN}(60 \mathrm{~mL})$ were added. The reaction mixture was stirred at reflux for 24 hours. After the solid was filtered off, the solvent was removed. The solid was dissolved in $\mathrm{CHCl}_{3}(100 \mathrm{~mL})$ and washed twice with $\mathrm{H}_{2} \mathrm{O}(100 \mathrm{~mL})$. The organic layer was dried over anhydrous $\mathrm{Na}_{2} \mathrm{SO}_{4}$ and evaporated to afford the crude product, which was isolated by flash column chromatography using petroleum ether/dichloromethane $(v: v=2: 1)$. The fractions containing the product were combined and concentrated to give NP5 (1.8 g, 78\%) as a light-yellow solid (m.p. $\left.>300{ }^{\circ} \mathrm{C}\right) .{ }^{1} \mathrm{H}$ NMR spectrum of NP5 is shown in Figure $\mathrm{S} 4$. The ${ }^{1} \mathrm{H}$ NMR $\left(600 \mathrm{MHz}, \mathrm{CD}_{2} \mathrm{Cl}_{2}, 298\right.$ K) $\delta(\mathrm{ppm}): 7.89-7.91(\mathrm{~d}, J=12,4 \mathrm{H}), 7.39-7.44(\mathrm{~m}, 4 \mathrm{H}), 6.90-6.99(\mathrm{~m}, 14 \mathrm{H}), 4.23-4.30(\mathrm{~m}, 8 \mathrm{H})$, 4.01-4.14 (m, 8H), 3.76-3.88 (m, 34H), 2.19-2.31 (m, 8H), 1.58-1.61 (t, $J=18,6 \mathrm{H}) ;{ }^{13} \mathrm{C}$ NMR spectrum of NP5 is shown in Figure S5. The ${ }^{13} \mathrm{C}$ NMR (150 MHz, $\left.\mathrm{CD}_{2} \mathrm{Cl}_{2}, 298 \mathrm{~K}\right) \delta(\mathrm{ppm}): 154.99,154.95,150.71$, $150.70,150.67,150.63,149.96,128.62,128.59$, 128.51, 128.43, 127.08, 127.04, 125.55, 125.44, 114.46, $114.38,114.25,113.63$, 113.60, 113.50, 105.72, 105.56, 68.22, 68.13, 64.24, 55.87, 55.79, 29.59, 29.49, $29.26,27.17,26.80$.
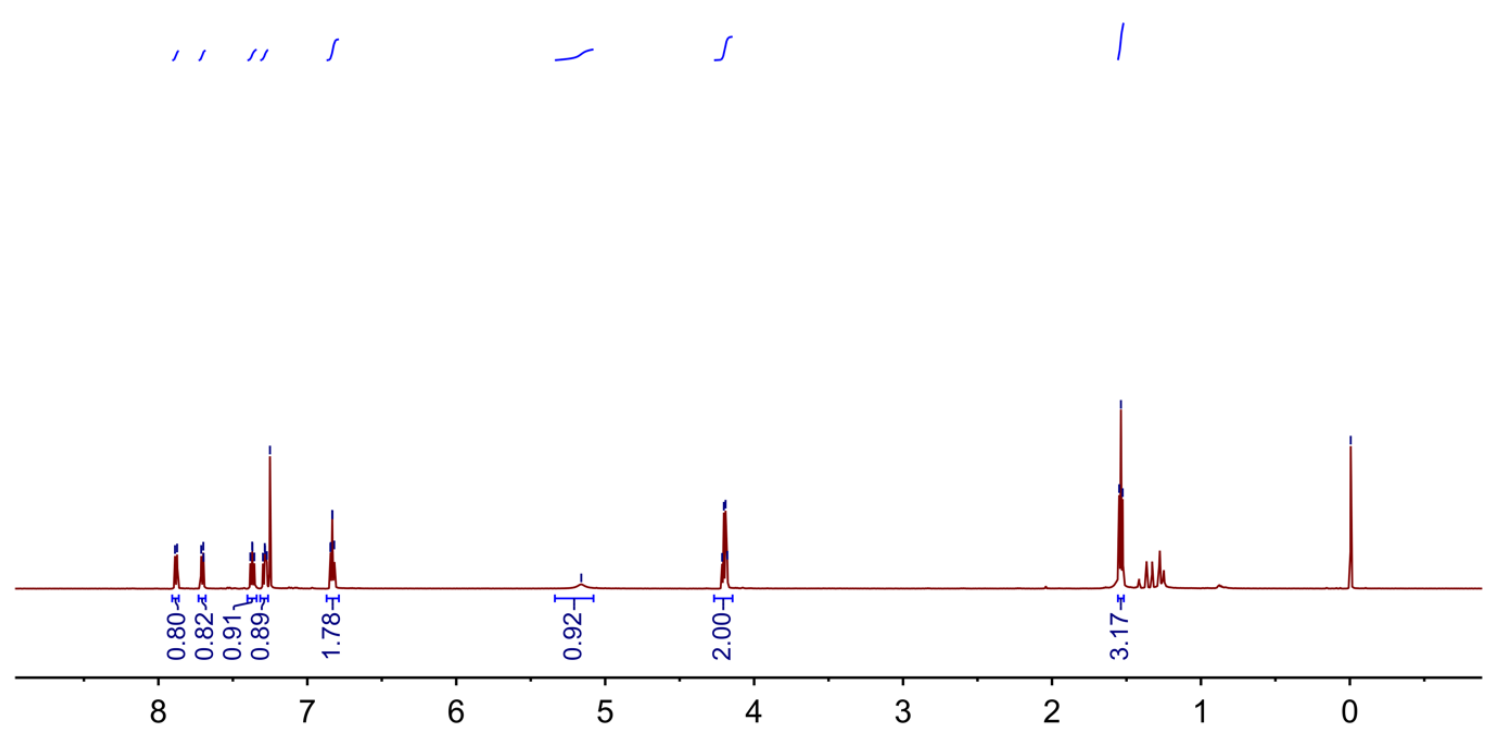

Figure S1. ${ }^{1} \mathrm{H}$ NMR spectrum $\left(600 \mathrm{MHz}, \mathrm{CDCl}_{3}, 298 \mathrm{~K}\right)$ of 2. 
misksis نَ

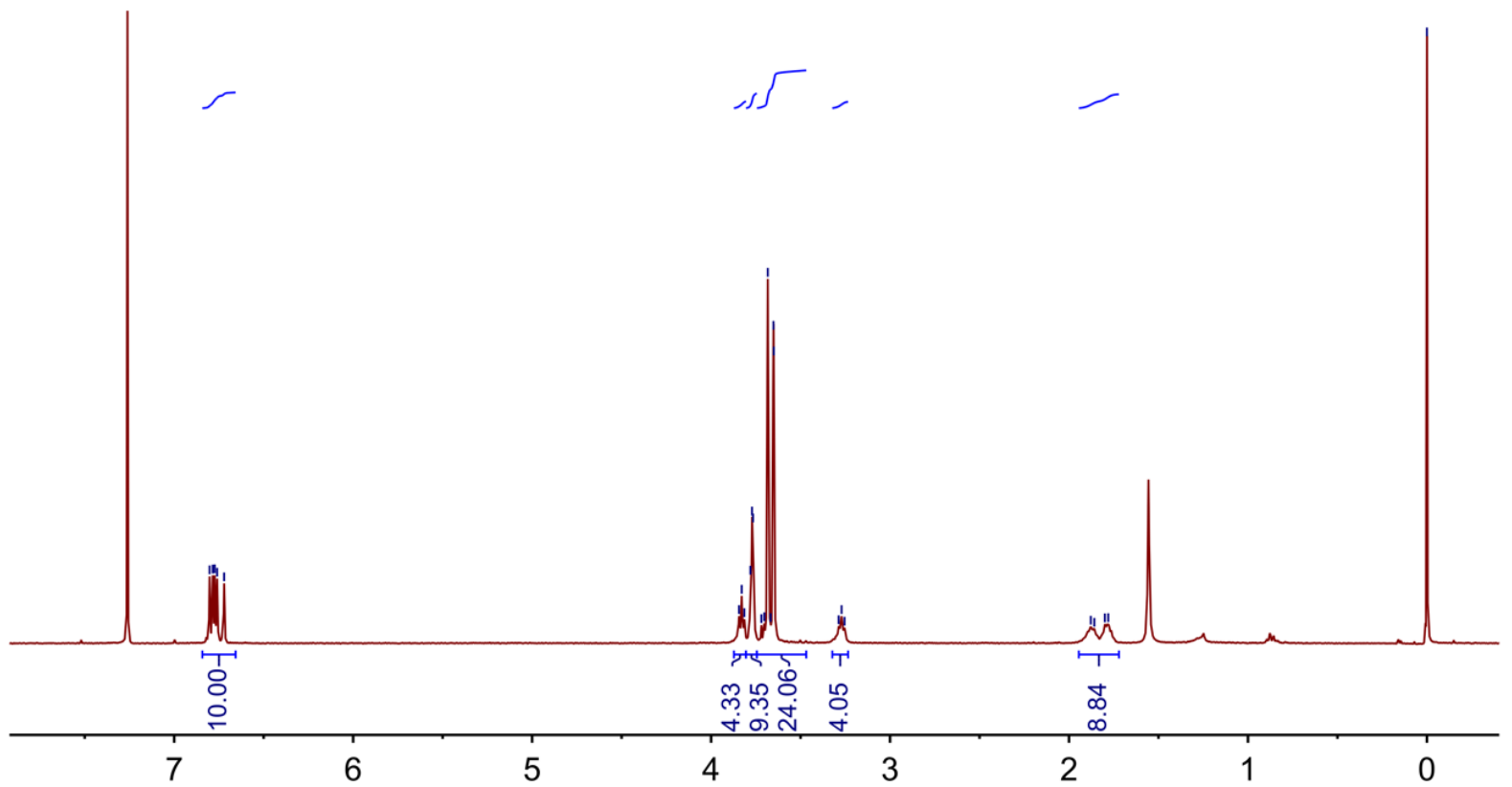

Figure S2. ${ }^{1} \mathrm{H}$ NMR spectrum $\left(600 \mathrm{MHz}, \mathrm{CDCl}_{3}, 298 \mathrm{~K}\right)$ of $\mathbf{1}$.

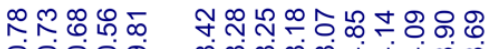

官官官官完

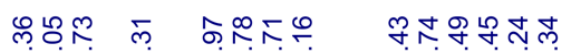

Nîn

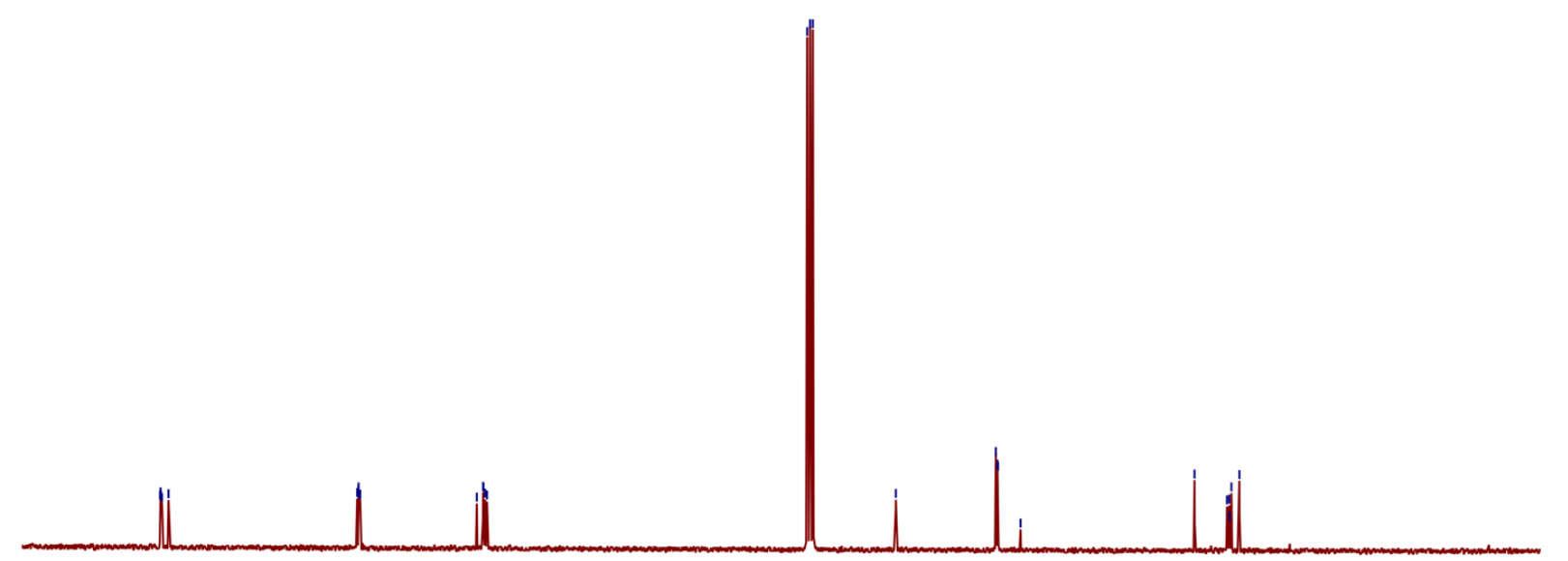

$\begin{array}{lllllllllllllllll}160 & 150 & 140 & 130 & 120 & 110 & 100 & 90 & 80 & 70 & 60 & 50 & 40 & 30 & 20 & 10 & 0\end{array}$

Figure S3. ${ }^{13} \mathrm{C}$ NMR spectrum $\left(150 \mathrm{MHz}, \mathrm{CDCl}_{3}, 298 \mathrm{~K}\right)$ of 1 . 


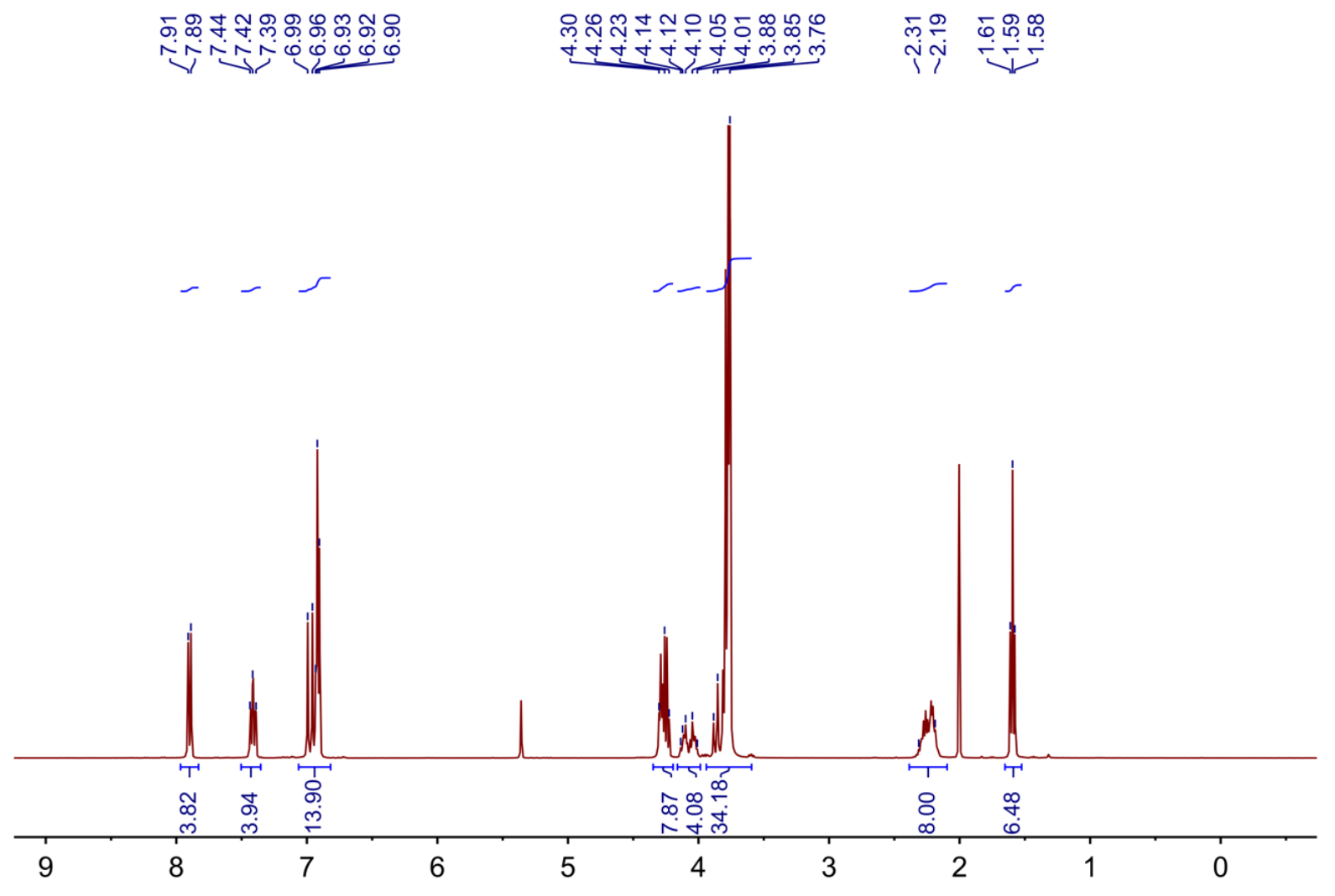

Figure S4. ${ }^{1} \mathrm{H}$ NMR spectrum $\left(600 \mathrm{MHz}, \mathrm{CD}_{2} \mathrm{Cl}_{2}, 298 \mathrm{~K}\right)$ of NP5.

\begin{tabular}{lllllllll}
\hline 160 & 140 & 120 & 100 & 80 & 60 & 40 & 20 & 0
\end{tabular}

Figure S5. ${ }^{13} \mathrm{C}$ NMR spectrum $\left(150 \mathrm{MHz}, \mathrm{CD}_{2} \mathrm{Cl}_{2}, 298 \mathrm{~K}\right)$ of NP5. 


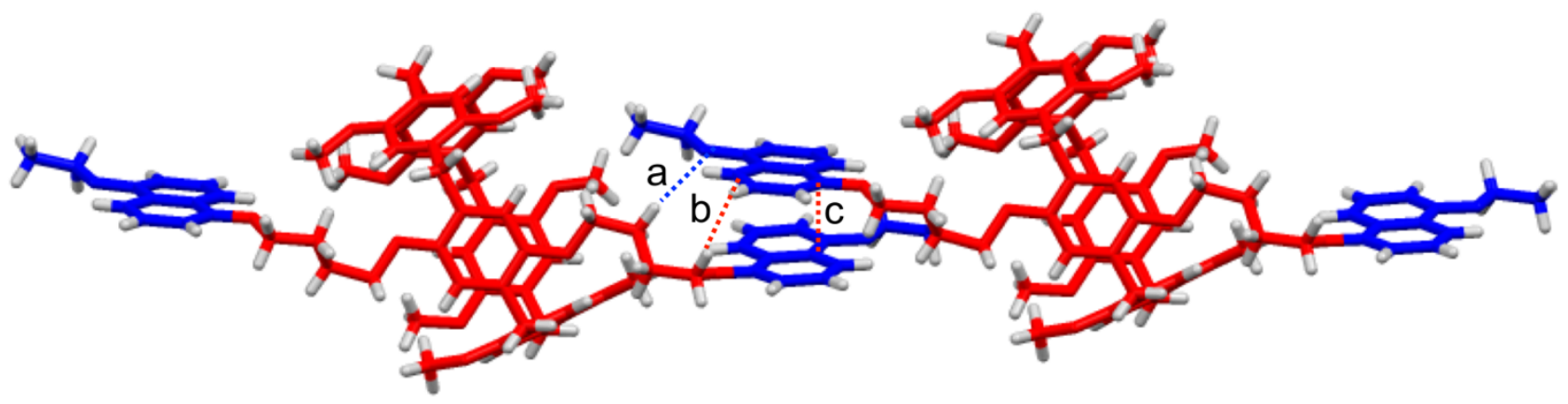

a: $2.635 \AA ;$ b: $2.800 \AA ;$ c: $3.373 \AA$

Figure S6. Single-crystal structure of NP5 in acetonitrile. NP5 molecules are connected by $\pi-\pi$ stacking interactions $(3.373 \AA)$ between the naphthalene groups on NP5. One $\mathrm{C}-\mathrm{H} \cdots \mathrm{O}$ interaction with $\mathrm{H} \cdots \mathrm{O}$ distance of $2.635 \AA$ and one $\mathrm{C}-\mathrm{H} \cdots \pi$ interaction with length of $2.800 \AA$ are also, which further helps the formation of the assembled structure.

4. Host-guest studies between NP5 and adiponitrile

(a)

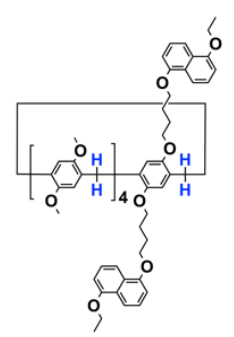

(b)

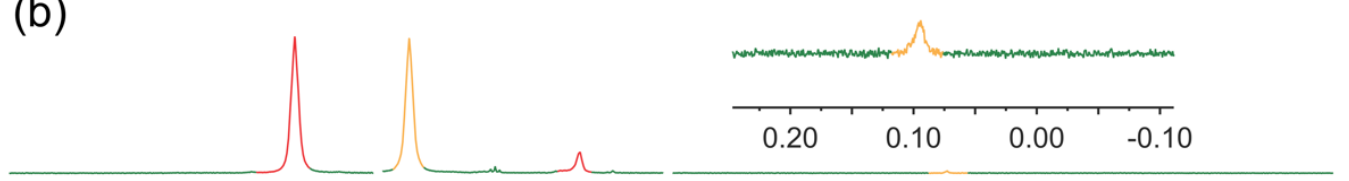

(c)

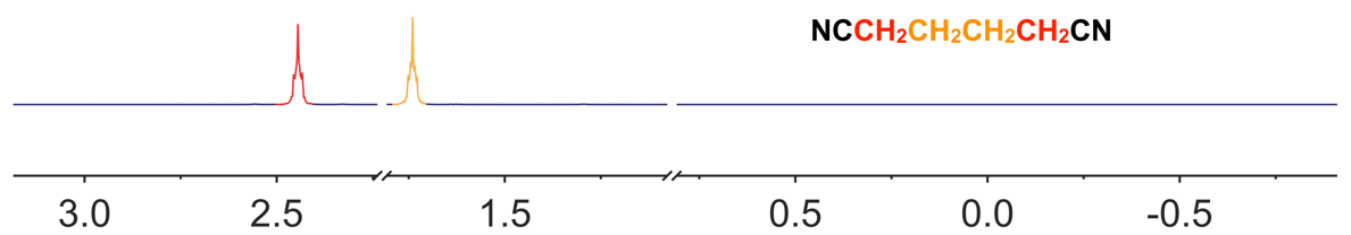

Figure S7. Partial ${ }^{1} \mathrm{H}$ NMR $\left(600 \mathrm{~Hz}, \mathrm{CD}_{3} \mathrm{CN}, 298 \mathrm{~K}\right)$ spectra of (a) NP5 (10.0 mM), (b) NP5 (10.0 mM) and adiponitrile $(10.0 \mathrm{mM})$, and $(\mathrm{c})$ adiponitrile $(10.0 \mathrm{mM})$. 


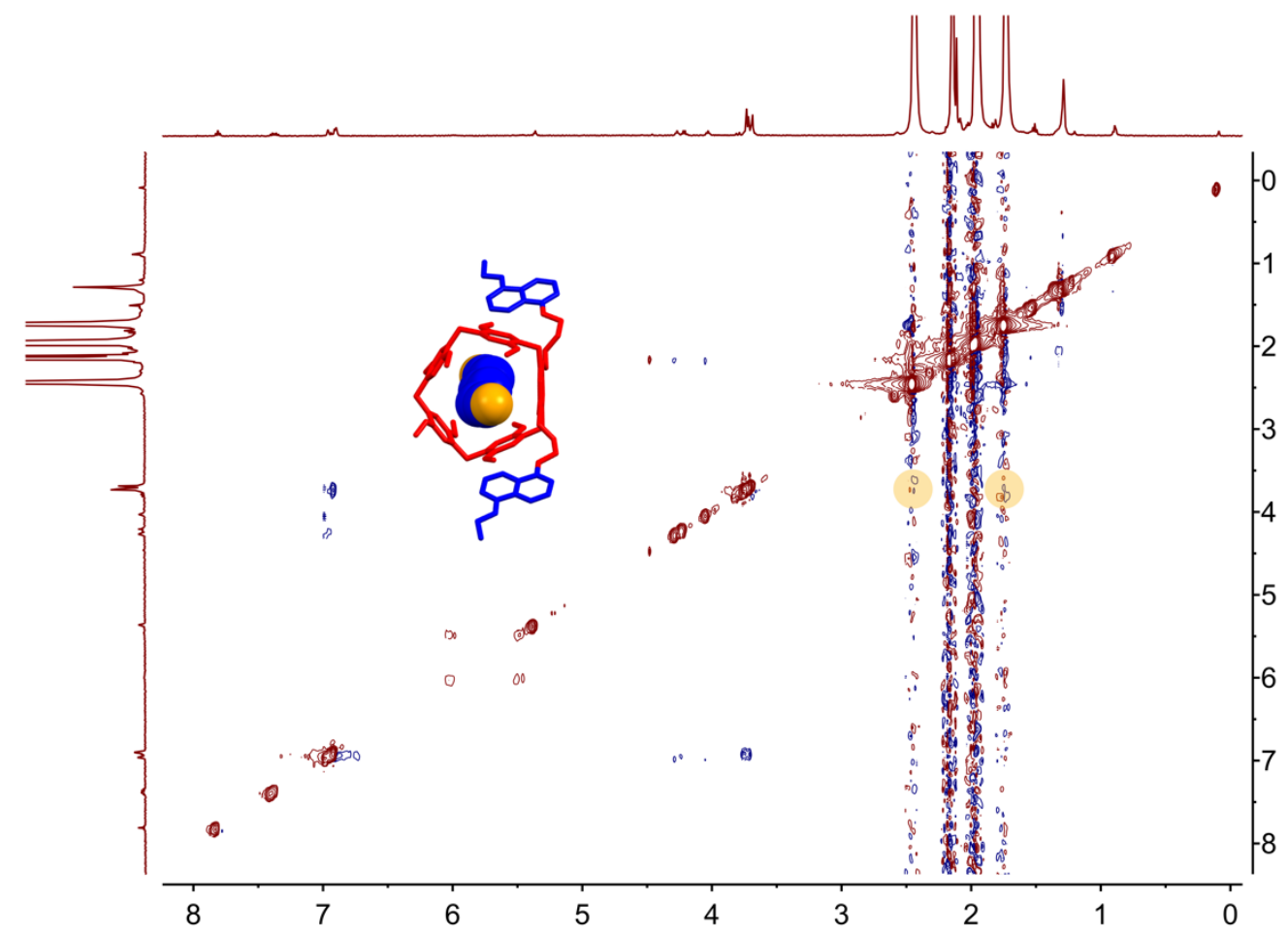

Figure S8. 2D NOESY NMR (500 MHz, CD $\left.{ }_{3} \mathrm{CN}, 298 \mathrm{~K}\right)$ spectrum of a solution of NP5 (10.0 mM) and adiponitrile $(10.0 \mathrm{mM})$.

5. Single-crystal structure of NP5/adiponitrile complex

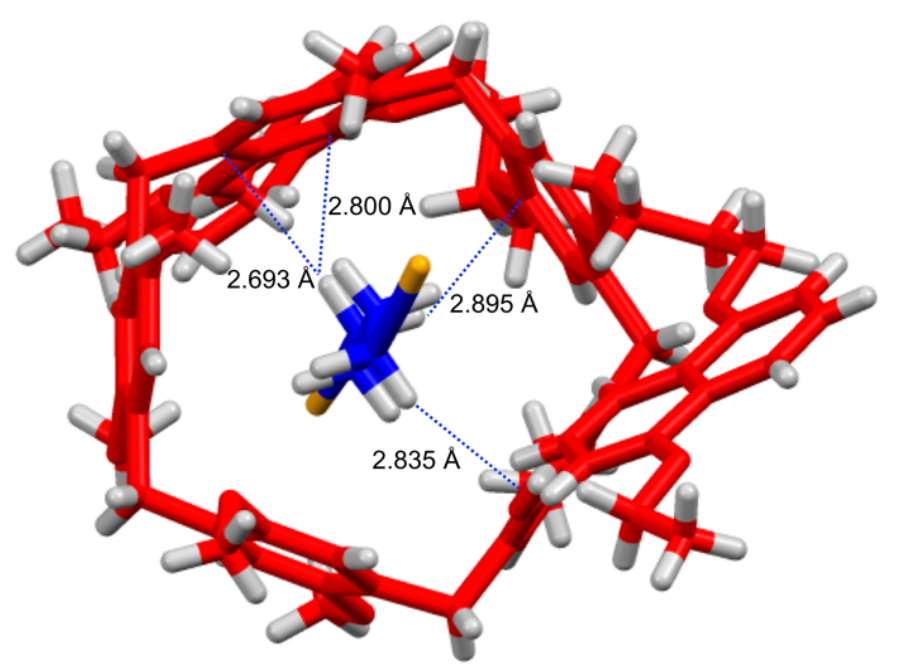

Figure S9. Single-crystal structure of NP5/adiponitrile complex. Three hydrogen atoms on the included adiponitrile molecule with $\mathrm{C}-\mathrm{H} \cdots \pi$ distances of $2.693-2.895 \AA$ are observed, indicating the existence of $\mathrm{C}-\mathrm{H} \cdots \pi$ interactions between the adiponitrile guest and the pillar[5]arene host cavity. 


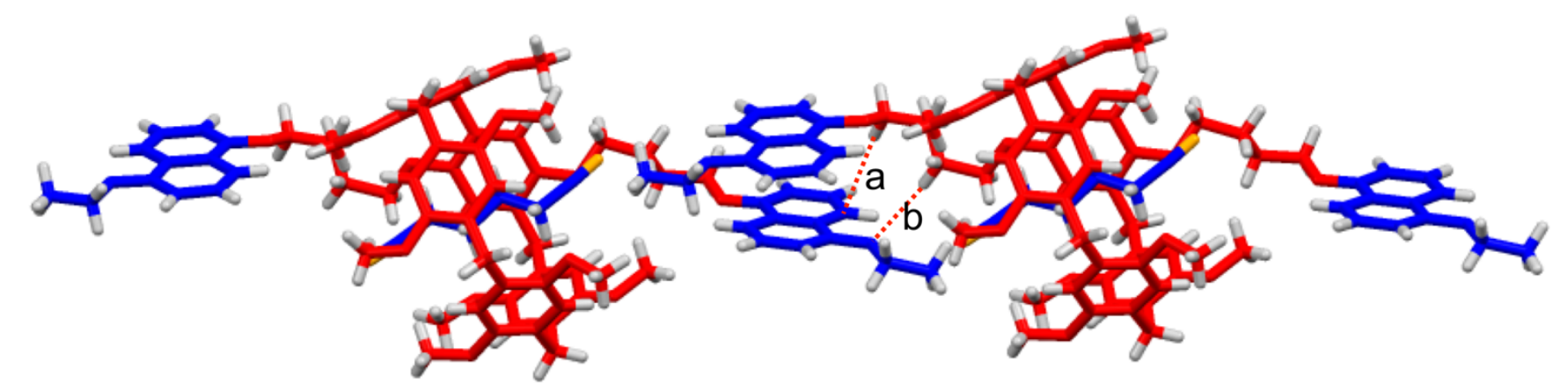

a: $2.860 \AA ;$ b: $2.687 \AA$

Figure S10. Single-crystal structure of NP5/adiponitrile. The pseudorotaxane units of NP5/adiponitrile single crystal are connected by $\mathrm{C}-\mathrm{H} \cdots \pi$ and $\mathrm{C}-\mathrm{H} \cdots \mathrm{O}$ interactions with the distances of 2.860 and $2.687 \AA$ to form linear side-chain polypseudorotaxane throughout the entire NP5/adiponitrile crystal structure.

\section{Powder X-ray diffraction studies}
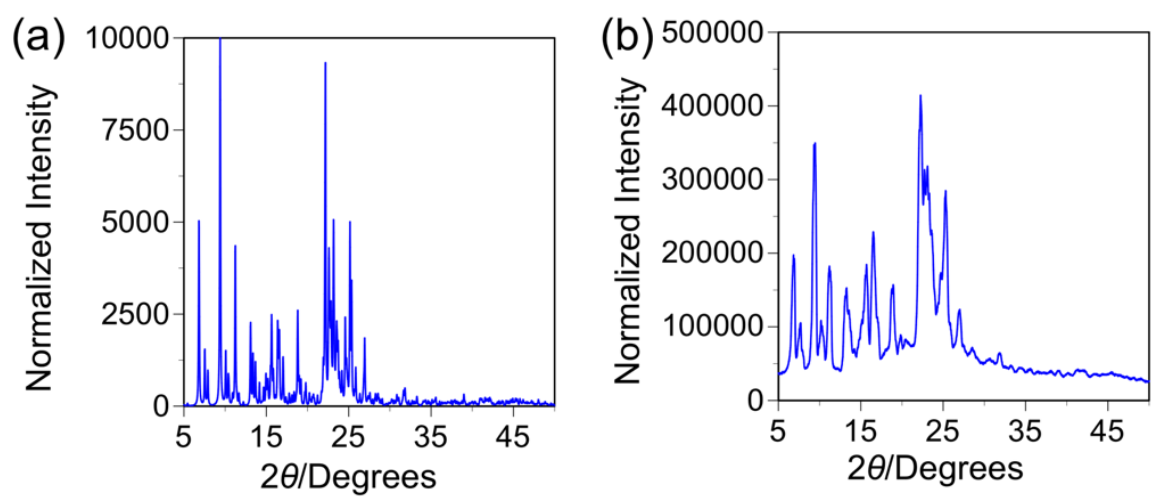

Figure S11. Powder X-ray diffraction patterns: (a) simulation data of NP5/adiponitrile single crystals; (b) NP5 single crystals after the adsorption of adiponitrile.

\section{Thermogravimetric analysis}
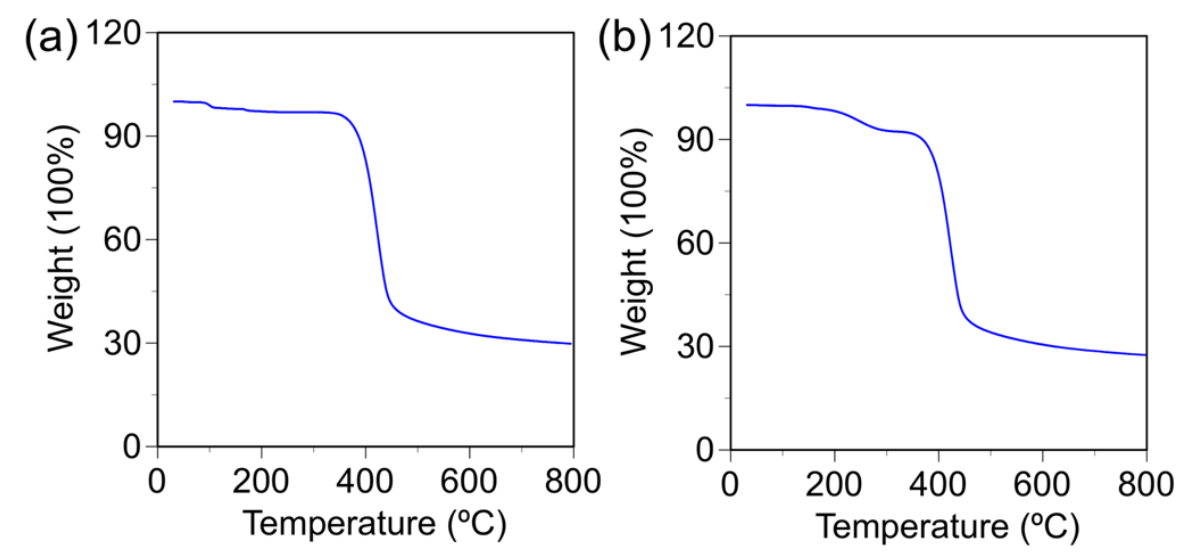

Figure S12. Thermogravimetric analysis: (a) NP5 single crystals; (b) NP5/adiponitrile single crystals. 
8. Amorphous solid of NP5 adsorption studies

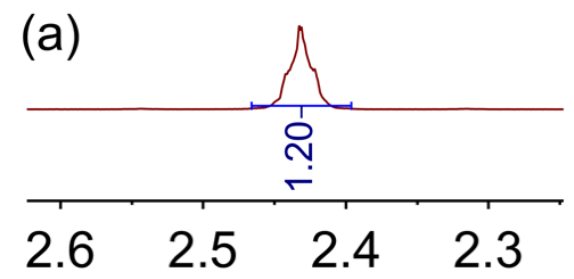

(b)
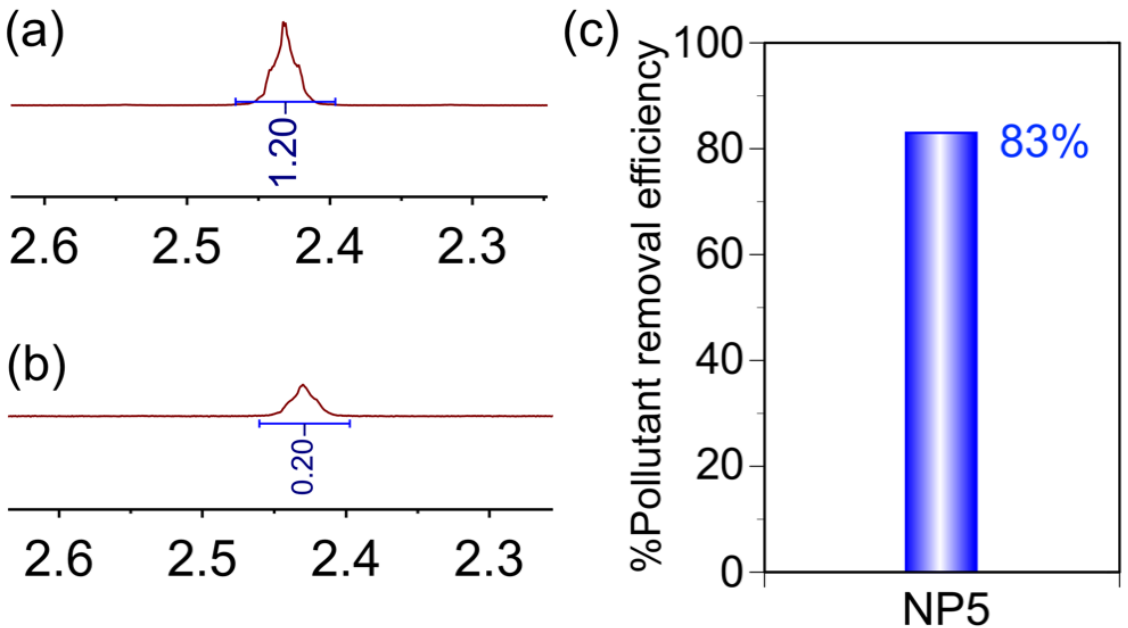

Figure S13. Partial ${ }^{1} \mathrm{H}$ NMR $\left(600 \mathrm{MHz}, \mathrm{D}_{2} \mathrm{O}, 298 \mathrm{~K}\right)$ spectra: (a) adiponitrile in stock $(c=1.00 \mathrm{mmol} / \mathrm{L})$; (b) adiponitrile after adsorption by amorphous solid of NP5. Acetic acid was used as internal standard $(c=1.00$ $\mathrm{mmol} / \mathrm{L}$ ). (c) The percentage removal efficiency of adiponitrile micropollutant from water by amorphous solid of NP5 determined after a contact time of 5 days.

\section{9. $\mathrm{NP5}$ regeneration studies}
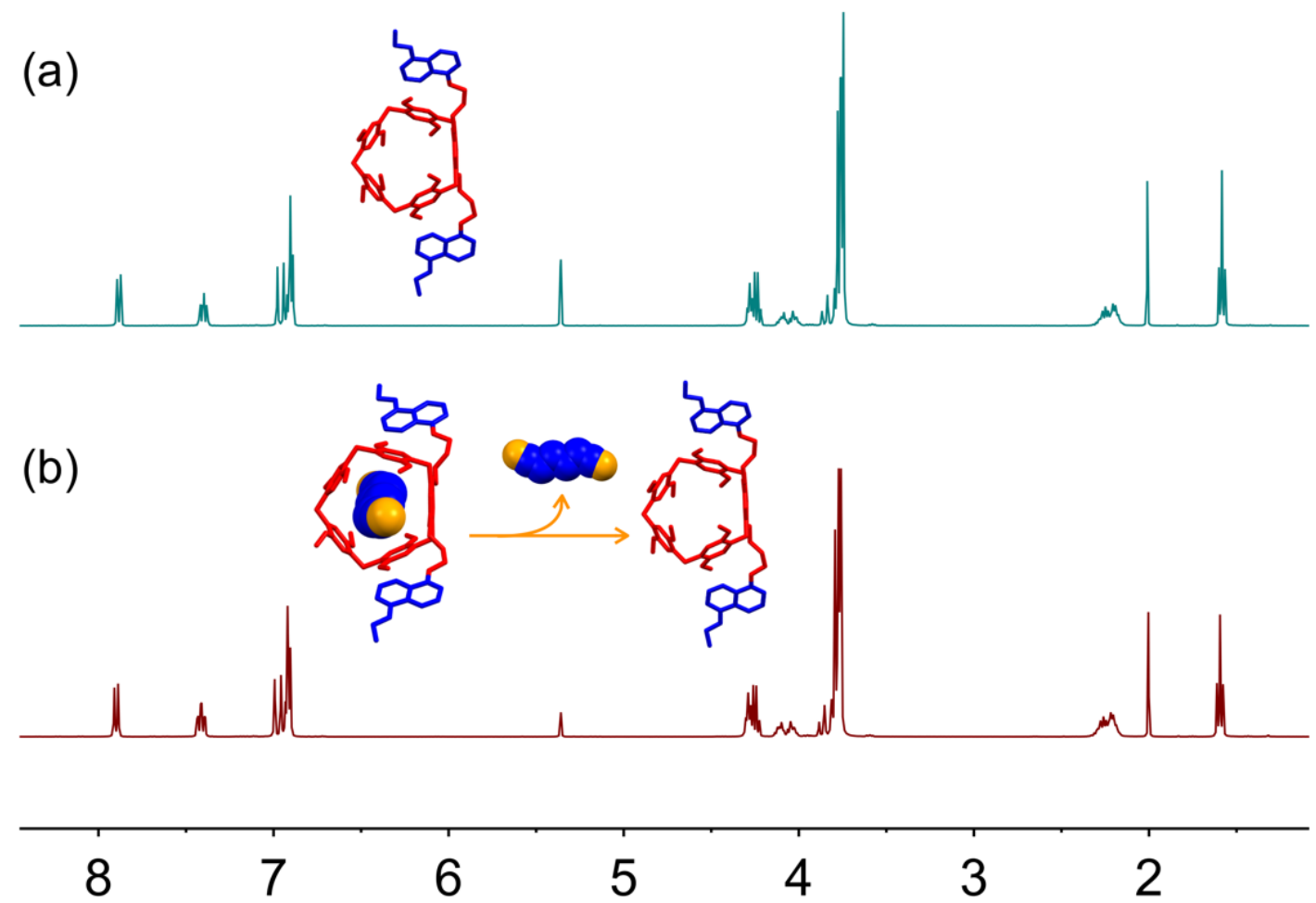

Figure S14. ${ }^{1} \mathrm{H}$ NMR $\left(600 \mathrm{~Hz}, \mathrm{CD}_{2} \mathrm{Cl}_{2}, 298 \mathrm{~K}\right)$ spectra of (a) initial NP5 and (b) regenerated NP5 from NP5/adiponitrile single crystals. 


\section{References:}

S1. Shi, B.; Guan, H.; Shangguan, L.; Wang, H.; Xia, D.; Kong, X.; Huang, F. A Pillar[5]arene-Based 3D Network Polymer for Rapid Removal of Organic Micropollutants from Water. J. Mater. Chem. A 2017, 5, $24217-24222$.

S2 Chen, J.-F.; Lin, Q.; Yao, H.; Zhang, Y.-M.; Wei, T.-B. Pillar[5]arene-Based Multifunctional Supramolecular Hydrogel: Multistimuli Responsiveness, Self-Healing, Fluorescence Sensing, and Conductivity. Mater. Chem. Front. 2018, 2, 999-1003.

\section{Crystallography Report}

Table S1. Experimental single crystal X-ray data for NP5 and NP5/adiponitrile complex structures.

\begin{tabular}{|c|c|c|}
\hline Name & NP5 & NP5/adiponitrile complex \\
\hline Crystallization Solvent & Acetonitrile & \\
\hline Color and description & Yellow, plate & Colourless, block \\
\hline Formula & $\mathrm{C}_{160} \mathrm{H}_{164} \mathrm{~N}_{5} \mathrm{O}_{28}$ & $\mathrm{C}_{164} \mathrm{H}_{180} \mathrm{~N}_{5} \mathrm{O}_{28}$ \\
\hline$M w$ & 2604.95 & 2669.12 \\
\hline Crystal Size $\left[\mathrm{mm}^{3}\right]$ & $0.49 \times 0.46 \times 0.36$ & $0.46 \times 0.39 \times 0.26$ \\
\hline Crystal System & triclinic & triclinic \\
\hline Space Group & $\mathrm{P}-1$ & $\mathrm{P}-1$ \\
\hline$a[\AA]$ & $11.7229(7)$ & $11.8512(5)$ \\
\hline$b[\AA]$ & $16.0910(8)$ & $16.3125(8)$ \\
\hline$c[\AA]$ & $19.5838(11)$ & $19.6256(10)$ \\
\hline$\alpha\left[^{\circ}\right]$ & $83.814(5)$ & $84.105(4)$ \\
\hline$\beta\left[^{\circ}\right]$ & $74.318(5)$ & $74.395(4)$ \\
\hline$\gamma\left[{ }^{\circ}\right]$ & $87.882(5)$ & $88.433(4)$ \\
\hline$V[\AA]$ & $3535.8(4)$ & $3634.9(3)$ \\
\hline$Z$ & 1 & 1 \\
\hline $\mathrm{D}_{\text {calcd }}\left[\mathrm{g} \mathrm{cm}^{-3}\right]$ & 1.223 & 1.219 \\
\hline Temperature $[\mathrm{K}]$ & 149.8 & $293(2)$ \\
\hline$\mu\left[\mathrm{mm}^{-1}\right]$ & 0.083 & 0.083 \\
\hline Measured reflections & 23642 & 24333 \\
\hline Independent reflections & 12902 & 13264 \\
\hline Parameters & 856 & 908 \\
\hline Restrains & 0 & 41 \\
\hline$F(000)$ & 1383 & 1423 \\
\hline$R$ (int) & 0.0370 & 0.0331 \\
\hline$R_{1}$ & 0.1188 & 0.1169 \\
\hline
\end{tabular}




\begin{tabular}{|l|l|l|}
\hline$w R_{1}$ (all data) & 0.2299 & 0.1865 \\
\hline$R_{2}$ & 0.0719 & 0.0630 \\
\hline$w R_{2}[I>2 \sigma(I)]$ & 0.1887 & 0.1505 \\
\hline Max. residual density $\left(\mathrm{e}^{\circ} \AA^{-3}\right)$ & 0.939 & 1.219 \\
\hline Goodness-of-fit $\left(F^{2}\right)$ & 1.036 & 1.023 \\
\hline CCDC & 1878273 & 1878272 \\
\hline
\end{tabular}

